\title{
Promoting university students' well-being and studying with an acceptance and commitment therapy (ACT)-based intervention
}

\author{
Nina Katajavuori ${ }^{1}$ (D) Kimmo Vehkalahti $^{2}$ (D) $\cdot$ Henna Asikainen $^{1}$ (D)
}

Accepted: 5 May 2021 / Published online: 14 May 2021

(C) The Author(s) 2021

\begin{abstract}
Students' poor well-being is a serious problem in higher education. In part, this problem is related to the problems in studying as poorer study skills are related to poorer well-being. Both students' study skills and their well-being should be enhanced in higher education, but effective ways to do this are needed. The aim of this study was to explore students' experiences of an ACT-based online, 8-week course on university students' well-being and studying. Data were collected in two ways: a) with qualitative data consisting of learning journals $(n=97)$ and with b) a pre- and post-questionnaire $(n=143)$ during the course. The students' scores on well-being, psychological flexibility, and time and effort management skills improved, and stress levels decreased during the course. Qualitative analyses showed that the students benefited from the course in many ways, both in terms of studying and wellbeing; their studying and time management skills had improved and they had learnt stress management skills and how to cope with their negative thoughts. We argue that supporting students' well-being, as well as their study skills with ACT-based course in higher education studies, can lead to more effective studying.
\end{abstract}

Keywords Well-being $\cdot$ Psychological flexibility $\cdot$ Study skills $\cdot$ Stress management $\cdot$ Acceptance and commitment therapy

Poor well-being has become a profound problem in higher education. In the United States, over $60 \%$ of college students have experienced serious anxiety, and over $50 \%$ have a psychiatric disorder (ACHA, 2011). Similar findings have been found throughout the world (Andrews \& Chong, 2011; Pistorello, 2012; Salmela-Aro \& Read, 2017; Storrie et al., 2010). In addition, study-related burnout has also been shown to be a problem in higher education and it has been associated with poor study progress (Asikainen et al., 2020; Salmela-Aro $\&$ Read, 2017). Thus, we argue that students' well-being should be taken into account in curriculums, and tools to enhance both well-being and study skills should be offered to all students.

Research has shown that psychological flexibility is an influential factor in well-being, performance and work satisfaction (Bond et al., 2013; Hayes, 2019; Hayes et al., 2006). Psychological flexibility can be defined as "the

Nina Katajavuori

nina.katajavuori@helsinki.fi

1 Centre for University Teaching and Learning (HYPE), Faculty of Educational Sciences, University of Helsinki, Helsinki, Finland

2 Centre for Social Data Science, Faculty of Social Sciences, University of Helsinki, Helsinki, Finland ability to contact the present moment more fully as a conscious human being, and to change or persist in behavior when doing so serves valued ends" (Hayes et al., 2006 , p. 7). It has been shown in many studies that psychological flexibility is positively related to better wellbeing and improved performance at the workplace (Flaxman et al., 2013; Puolakanaho et al., 2020). The research concerning the role of psychological flexibility in studying is growing in the higher education context. Recent studies have shown that psychological flexibility has a strong relation to student engagement and progression in studies (Asikainen, 2018; Asikainen et al., 2018; Salmela-Aro \& Read, 2017). In addition, as part of students' counseling, successful interventions based on the improvement of psychological flexibility have been made to increase students' well-being in higher education (Howell \& Passmore, 2019; Levin et al., 2017; Levin et al., 2020; Räsänen et al., 2016). A recent meta-analysis, however, found that there is a need to study the effects of Acceptance and Commitment Therapy (ACT) interventions further to analyze their effects on student well-being (Howell \& Passmore, 2019). Qualitative detailed knowledge about students' experiences of the effects of ACTbased interventions is also missing. In addition, interventions in higher education explore changes in students' 
well-being, but they do not take into account how these interventions support students' studying, although it has been shown that problems in study skills are related to a risk of burnout (Asikainen et al., 2020). Furthermore, although there is literature concerning ACT-based interventions in college and higher education areas, little research has been conducted on how students themselves experience the effects of an intervention course which combines ACT-based as well as study skills exercises. The aim of this study is to explore students' reflections of how an ACT-based intervention course which aimed to promote students' well-being and study skills supported their wellbeing and studying.

\section{Psychological Flexibility and Organized Learning in Promoting Well-Being}

The concept of psychological flexibility originated in the theoretical framework of Acceptance and Commitment therapy (Hayes et al., 2006). ACT aims to increase psychological flexibility and support individuals to face all aspects, both positive and negative, and live a value-based life (Hayes et al., 2006). Psychological flexibility can be defined as the ability to contact the present moment more fully as a conscious human being, and to change or persist in behavior when doing so serves valued ends (Hayes et al., 2006, p.7). Thus, psychologically flexible people act according to their own values despite the negative sensations that might be evoked (Bond et al., 2010).

Psychological flexibility is the result of engagement with the six overlapping core processes, namely acceptance, cognitive defusion, being present, self as context, values, and committed action (Hayes et al., 2006). Acceptance means embracing negative feelings or thoughts without trying to change them (Hayes et al., 2006). Negative thoughts or feelings are noticed and one takes another perspective to these feelings so that value-based action is possible (Hacker et al., 2016). Exploration of values is also a central part of psychological flexibility. Values offer guidance in making experiences in life meaningful and in helping to guide actions in a way that offers long-term satisfaction (Hayes et al., 2006). Cognitive defusion can be defined as the process through which one's relationship to negative thoughts is altered so that a person is able to see thoughts just as thoughts and not as a truth about themselves (Luoma \& Hayes, 2008). Being present means paying full attention and focusing on the different events or thoughts or feelings as they occur (Hayes et al., 2006). It is a parallel process with the core process of self-as context, which means seeing oneself as a context in which feelings and emotions can be monitored and thus seen as a separate part of oneself (Hayes, 2019). This process of self-as context can also increase self-knowledge (Hayes et al., 2020). In addition, committed action can be defined as action based on one's own values despite the negative feelings and thoughts that might be evoked (Hayes et al., 2006).

\section{Psychological Flexibility and Well-Being}

Psychological flexibility has an effect on well-being (Bond et al., 2013; Hayes, 2019; Hayes et al., 2006). Defining well-being, moreover, is challenging as there are several definitions for well-being (Dodge et al., 2012). Traditionally, subjective well-being is divided into hedonic (feeling good about or having positive emotions toward one's life) and eudaimonic (functioning well in life as an individual) wellbeing (Deci \& Ryan, 2001). The hedonic tradition emphasizes emotional well-being whereas the eudaimonic tradition focuses on psychological and social well-being. One central model of well-being defines it as having three parts, namely emotional, psychological, and social well-being (Keyes, 2002). Emotional well-being relates to satisfaction in life and the positive emotions of life. Psychological well-being relates to how individuals view themselves as functioning in life, including for example self-acceptance, a sense of mastery and competence, positive relationships with others, a sense of goal-directedness in life, and a sense of autonomy (Ryff, 1989). Social well-being also refers to positive functioning from a social perspective and it includes social coherence, social acceptance, social actualization, social contribution, and social integration (Keyes, 1998).

Recent research has shown that promoting psychological flexibility improves all these aspects of well-being: emotional, psychological, and social well-being (Räsänen et al., 2016). ACT-based interventions have been shown to be effective in improving mental health and well-being, and a wide range of psychological problems like reducing depression, anxiety and somatic health problems (A-Tjak et al., 2015; French et al., 2017; Ruiz, 2010). Furthermore, the study by Viskovich and Pakenham (2018) showed that participation in ACTintervention was associated with improved mental health skills (like acceptance, defusion, valued living, and mindfulness), which show a potential in improving well-being, selfcompassion, life satisfaction, and distress. Psychological flexibility skills can be crucial elements also in reducing jobrelated burnout (Puolakanaho et al., 2020). It has also been suggested that ACT-based interventions are effective in the treatment of common mental health difficulties (Hacker et al., 2016).

\section{Promoting Psychological Flexibility in Higher Education}

ACT-based interventions have been studied in the higher education context with different kinds of implementations 
comprising face-to-face interventions with workshops (Danitz \& Orsillo, 2014; Grégoire et al., 2018), face-to-face meetings with online exercises (Räsänen et al., 2016), and guided online interventions (Levin et al., 2017; Viskovich \& Pakenham, 2018). The results of these ACT interventions have been promising in terms of improving university students' wellbeing. The study by Danitz and Orsillo (2014) showed that the first-year students who participated in an ACTintervention workshop reported significantly less depression and more acceptance than the control group. A study by Grégoire et al. (2018) also showed that university students who participated in ACT-intervention with workshops reported greater well-being, school engagement, and lower stress, anxiety and depression symptoms than the control group. Promising results of online interventions have also been reached, like the study by Räsänen et al. (2016), which showed that the intervention participants who were offered face-to-face meetings and online exercises during a fiveweek period had significantly improved in their scores on well-being, life satisfaction and mindfulness skills than the control group. Self-reported stress and symptoms of depression were also significantly reduced compared to the control group. In addition, the study by Levin et al. (2017) reported similar results showing that ACT intervention improved on overall distress, general anxiety, social anxiety, depression, academic concerns, and positive mental health compared to the control group. The study by French et al. (2017) confirmed that all the formats of intervention can be effective if they include some form of guidance.

In addition to well-being and mental health, psychological flexibility also has a central influence in success in higher education. It is related to positive emotions in learning (Asikainen et al., 2018), integration into studying (Asikainen, 2018), and study progression (Asikainen, 2018; Asikainen et al., 2018). Psychological flexibility is also related to students' self-regulation in learning (Asikainen, 2018; Asikainen et al., 2018; Eisenbeck et al., 2019) and it has been found to be essential in decreasing procrastination (Dionne, 2016; Gagnon et al., 2016). Thus, it seems that psychological flexibility is related to both well-being and more effective studying. However, there is a limited amount research about the relation of psychological flexibility to learning and study processes.

Recent research has also shown that students' learning and studying processes are related to their well-being and that organized studying has a positive relationship to well-being (Asikainen et al., 2020). Self-regulated learning, including skills such as time management and making an effort, can be defined as taking control and monitoring one's own learning process (Vermunt, 1996). Thus, self-regulated learning is similar to organized studying, which can be defined as time and effort management when studying. Organized studying has been shown to be important for successful completion of university programs (Asikainen et al., 2014; Hailikari \& Parpala, 2014; Rytkönen et al., 2012). Students who can organize themselves and are self-guided in their studying proceed more successfully. Students' time management skills can be improved through interventions in which students practice organizing skills (Häfner et al., 2014).

Taken together, the results of different implementations of $\mathrm{ACT}$ interventions offer a valuable way to promote university students' well-being and mental health. Furthermore, psychological flexibility and students' time and effort management skills play an important role at university and in fostering student well-being, and thus, both should be promoted during higher education. However, previous research concerning ACT interventions has focused on studying the changes in students' well-being and mental health during these interventions, but more research is needed to explore in more detail how these interventions promote their well-being. There has also been little qualitative research that emphasizes students' own experiences about the effects of interventions that aim to promote psychological flexibility. Although ACT-based interventions in the higher education context have been conducted, interventions combining both the ACT-based approach and study skills have not been conducted. The intervention course in this study aims to promote student well-being with ACTbased exercises combined with practicing study skills. In addition, the present study aims to explore students' reflections on the course using a qualitative approach.

\section{Aim of the Study}

The aim of this study is to explore students' reflections on completing an ACT-based course designed to improve studying and well-being, and to examine students' reflections on how the course supported their well-being and studying. The research question of this study is:

\section{How Do Students' Experience and Describe the Change in their Well-Being and Studying during the Intervention Course?}

Based on previous research (Danitz \& Orsillo, 2014; Howell \& Passmore, 2019; Räsänen et al., 2016), we expected that students would experience and describe improvements in their well-being and psychological flexibility. We also expected that students would experience improvements in their time management skills as previous studies have shown that these can be improved by intervention courses (Asikainen et al., 2019; Häfner et al., 2014). Based on previous research we also expected different students to have a variety of experiences as it has been shown that students can experience the effects of 
an ACT-based course differently (Asikainen et al., 2019; Danitz et al., 2016).

\section{Methods}

\section{Participants}

This study was conducted among students in a voluntary course that aimed to promote students' well-being and study skills. This course was run in spring 2018 in University of Helsinki, Finland. Students were enrolled in the course via student organizations, program leaders and teachers, advertising mainly on the Life Science Campus of University Helsinki. A total of 184 students completed this course. Of these students, 143 students responded to all questionnaires before the course and seven weeks later at the end of the course; they also gave permission for their data to be used in the research. Of these students, 125 were female and 18 were male. Of the total of 143 students, 97 gave permission for their learning journals to be used in the present study (more about the study instruments below).

\section{Measures}

Students' well-being was measured with GB-CORE (Evans et al., 2005), consisting of 14 items on the scale 0 "never" through 4 "most of the time or all the time." GB-CORE measures one's general psychological well-being and it has been shown to be a reliable and valid questionnaire to measure this psychological well-being (Evans et al., 2005). The measure included questions which measured both well-being and illbeing like "I have achieved the things I wanted to," "I have felt able to cope when things go wrong," and "I have felt unhappy." Lower scores denote better well-being after orienting the items in the same direction. Hence, the scale was called "illbeing."

Organized studying was measured with four Likert items on the scale 1 "disagree" through 5 "agree" (Parpala \& Lindblom-Ylänne, 2012), including four items measuring the organized studying scale (for example, "On the whole, I've been systematic and organized in my studying"). Higher scores denote better organized studying.

Psychological flexibility was measured according to a Work-Related Acceptance and Action Questionnaire (WAAQ) (Bond et al., 2013) that was modified and tested in a university context (Asikainen et al., 2018). It consisted of seven Likert items on the scale 1 "disagree" through 5 "agree" (for example, items like "I can admit to my mistakes in studying and still be successful" and "I can study effectively, even when I doubt myself"). Higher scores denote better psychological flexibility.
Stress was measured with the Perceived Stress Scale (PSS) instrument (Cohen et al., 1983), which is a well-established measure developed to measure a person's perceived stress. The items in this instrument are generic, and thus this instrument is applicable in measuring one's stress in different contexts (Cohen et al., 1983). The measure included such questions as: "In the last month, how often have you felt that you could not cope with all the things you had to do?" and "In the last month, how often have you felt that you were on top of things?" This instrument consists of ten items on the scale 0 "never" to 5 "very often." Higher scores denote higher stress, after orienting the items in the same direction. Students' experiences of the course and its effect on their studying was measured with Likert-type questions of four items on the scale "totally disagree" to "totally agree" and the authors' analyses of the learning journals.

Students' experiences of the course were analyzed by exploring the students' final reflective journal, which they completed in the last week of the course. Students were instructed to write a reflective journal of 2-3 pages, where they were instructed to reflect on their experiences of how the course affected their studying and well-being. Students were asked to consider which elements on the course had helped them, or not helped them and if so, why. Students' experiences of the course were also studied at the end of the course by using a questionnaire consisting of Likert items related to the experiences of the course (see Fig. 1).

\section{Analysis}

The quantitative analyses were conducted with Spss Statistics version 25 . Of the 143 students, only 17 students had a maximum of one missing value per measure, with no systematic pattern of missingness. Therefore, missing values were replaced with the individuals' means of the measures. Sum scales were formulated from the items measuring ill-being, stress, psychological flexibility and organized studying because all are widely used and robust scales. In addition, Cronbach's alphas were calculated, and their relation was explored with Pearson's correlation. The Likert-type items and questions comprising students' experiences of the effects of the course were examined using descriptive statistics. A repeated measures general linear model (Nimon, 2012) was used to determine whether there were any differences in the four dependent variables (students' well-being, organized studying, psychological flexibility, and stress) when measured before and after the course.

Students' experiences of the course that affected their wellbeing and studying were analyzed from these final reflective learning journals $(n=97)$ by following the principles of qualitative content analysis (Elo \& Kyngäs, 2008; Pope et al., 2000). The first and the third authors were responsible for the analysis, analyzing half of the journals each. The analysis 
Fig. 1 Students' experiences of the course

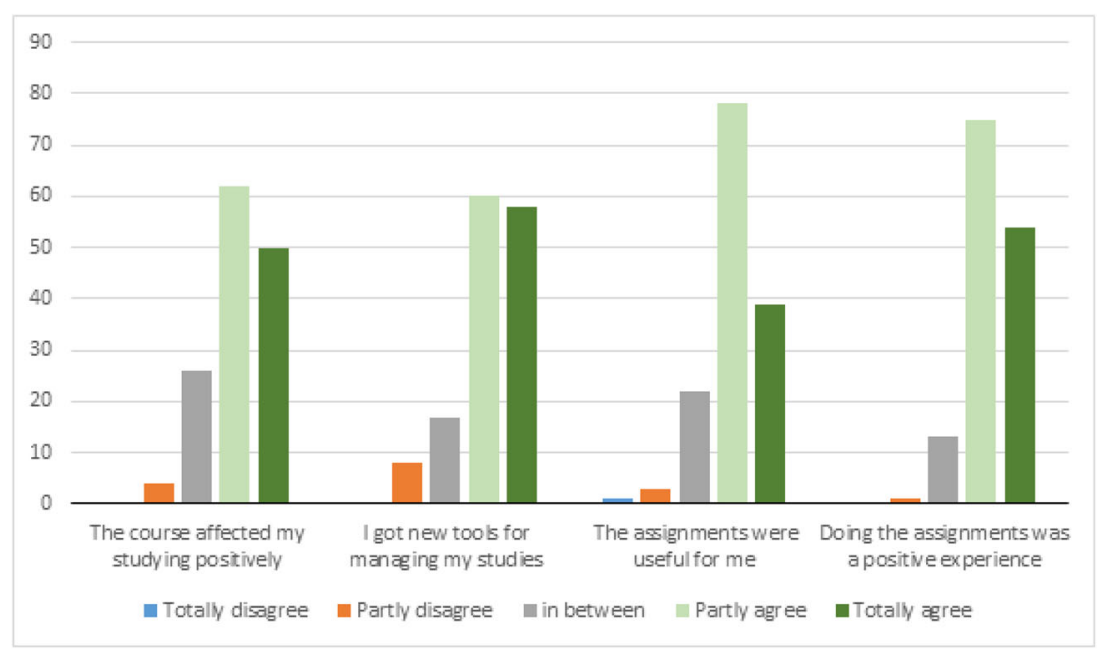

included three complementary phases to incorporate the negotiation of the meaning of the learning journal segments, clarification of the categorization, and peer agreement. All the text segments in which students described how this course had or had not affected their studying by giving tangible examples, were identified and coded for the analysis. One text segment could include more than one kind of course benefit. The authors independently coded portions of the journals to generate preliminary codes, and grouped and categorized codes according to their meanings, similarities and differences. After discussions and after elaborating the categorization, the first and third authors analyzed the remainder of the journals. The categories which were formed during the first stage (22) were reduced in number by grouping them together into nine categories.

The constant comparison technique was applied throughout the data analysis. In this process, each item was checked or compared with the rest of the data to establish analytical categories (Pope et al., 2000). The trustworthiness of the analysis was ensured by the first and third authors having constant discussions about categories, similarities, and divergent opinions (see Elo et al., 2014). Discussions were continued until consensus was reached. Finally, the first author checked randomly selected journals to ensure the categorization and trustworthiness of the analysis.

\section{Context of the Study}

The course in which students in this study took part was an optional seven-week course that aimed to foster students' well-being and was organized for university students. The course was a web-based ACT-based course for which students earned 3 ECTS $(1$ ECTS $=27 \mathrm{~h}$ of work). A headstedt.com platform was applied to this course. This course progressed week by week which its own theme related to psychological flexibility and study processes (see Table 1). Six of the modules were related especially to psychological flexibility and one of the modules especially to study skills. The course also included individual work in practicing psychological flexibility skills as well as study skills on a weekly basis. Each week included an introduction to the theme of the week, individual experimental and reflective exercises, and some group discussions on a web-based platform. Students wrote short reflective essays at the end of each week in which they described the exercises they had practiced during the week. Students gave each other anonymous encouraging peer feedback of the essays after each week. At the end of the course, students wrote a longer reflective journal in which teachers also gave feedback. The course in the present study was a similar and earlier version of the course design, and a more detailed description of the course is presented by Asikainen and Katajavuori (2021).

\section{Results}

First, we explored students' responses to the questionnaires at the beginning and the end of the course and explored the change in these responses. Cronbach's alphas of the scales were good, ranging from 0.70 to 0.90 (see Table 2). The correlational analysis showed that all the components were statistically significantly related to each other. Psychological flexibility correlated positively with organized studying and negatively with perceived stress and ill-being in both measurements $(p<.001)$. Stress also correlated positively with ill-being $(\mathrm{p}<.001)$ and negatively with organized studying $(p<.001)$. In addition, there was a negative correlation between ill-being and organized studying $(\mathrm{p}<.001)$. The correlations can be seen in Table 3. 
Table 1 Content and themes of the intervention course

\begin{tabular}{|c|c|c|c|}
\hline $\begin{array}{l}\text { Module of the } \\
\text { course }\end{array}$ & Theme and core process & Practices and exercises & $\begin{array}{l}\text { Reflections and } \\
\text { feedback }\end{array}$ \\
\hline $\begin{array}{l}\text { Introduction } \\
\text { module }\end{array}$ & $\begin{array}{l}\text { Introduction to the course and its } \\
\text { themes and practices }\end{array}$ & $\begin{array}{l}\text { Evaluations of one's wellbeing and study processes } \\
\text { Setting a goal to the course: What would you like to improve in your studying } \\
\text { during this course }\end{array}$ & \\
\hline Module 1 & $\begin{array}{l}\text { Theme: What is important } \\
\text { Core process: Values }\end{array}$ & $\begin{array}{l}\text { Time-usage follow-up hour by hour for a week (studying, spare time, } \\
\text { sleeping etc) } \\
\text { Considering one's values and important things in life }\end{array}$ & \\
\hline Module 2 & $\begin{array}{l}\text { Theme: Focusing on the present } \\
\text { Core process: Being present and } \\
\text { acceptance }\end{array}$ & $\begin{array}{l}\text { Practices related to being in contact with the present } \\
\text { Relaxation exercises }\end{array}$ & \\
\hline Module 3 & $\begin{array}{l}\text { Theme: Power of thoughts } \\
\text { Core process: Cognitive defusion and } \\
\text { self as context }\end{array}$ & Practices related to seeing one's thoughts as thoughts and not as facts & \\
\hline Module 4 & $\begin{array}{l}\text { Theme: Coping with studying, study } \\
\text { techniques } \\
\text { Core process: Committed actions }\end{array}$ & $\begin{array}{l}\text { Introductions and material about study skills and how to improve them } \\
\text { Peer group discussions about studying and effective study techniques and } \\
\text { how to apply these to one's studying }\end{array}$ & \\
\hline Module 5 & $\begin{array}{l}\text { Theme: Acceptance and } \\
\text { self-compassion } \\
\text { Core process: Acceptance and self as } \\
\text { context }\end{array}$ & Practices related to acceptance and self-compassion towards oneself & \\
\hline Module 6 & $\begin{array}{l}\text { Theme: Value-based actions } \\
\text { Committed actions }\end{array}$ & $\begin{array}{l}\text { Taken actions to practice value-based actions despite the negative thoughts } \\
\text { and feelings one might have }\end{array}$ & \\
\hline Module 7 & Concluding module & $\begin{array}{l}\text { Evaluations one's wellbeing and study processes } \\
\text { Final reflective journal - summarizing the course and experiences during it }\end{array}$ & \\
\hline
\end{tabular}

\section{Change in the Students' Experiences during the Course}

The result of the repeated measures general linear model was statistically significant (Multivariate F-tests, $p<.001$ ), suggesting that there is a difference in the combined four dependent variables (students' well-being; organized studying; psychological flexibility; and stress) between the two time points of the study, that is, before and after the course. The univariate tests also show that the changes in each of the dependent variables between the two time points (see Table 2) are statistically significant (Univariate F-tests, $\mathrm{p}<.001)$. Students' experiences of ill-being and stress are significantly lower after the course. Similarly, the students' experience of organized studying and psychological flexibility were higher at the end of the course. The mean differences can be seen in Table 2 .

\section{Students' Experiences about the Course}

A questionnaire at the end of the course was used to explore students' experiences of the course. Students' $(n=$ 143) experiences of the course were very positive (Fig. 1). A total of $90 \%$ of the students partly or totally agreed that they had a positive experience of the exercises in the course, and $82 \%$ of the students partly or totally agreed that the assignments were useful to them. In addition, $83 \%$ of the students totally or partly agreed that they received new tools for managing in their studying, and $79 \%$

Table 2 The differences in Means between two measurements

\begin{tabular}{|c|c|c|c|c|c|c|c|c|c|c|c|}
\hline & \multicolumn{3}{|l|}{ Before } & \multicolumn{3}{|l|}{ After } & \multirow[b]{2}{*}{$\alpha$} & \multirow[b]{2}{*}{$\mathrm{F}$} & \multirow[b]{2}{*}{ Range } & \multirow[b]{2}{*}{$\mathrm{p}$} & \multirow[b]{2}{*}{ Cohen's d } \\
\hline & Mean & SD & $\alpha$ & Range & Mean & SD & & & & & \\
\hline Psychological flexibility & 2.92 & 0.79 & 0.87 & 4.00 & 3.30 & 0.77 & 0.90 & 40.649 & 3.57 & $<0.001$ & 0.58 \\
\hline Ill-being & 1.47 & 0.58 & 0.84 & 3.43 & 1.15 & 0.64 & 0.89 & 35.941 & 3.29 & $<0.001$ & -0.81 \\
\hline Stress & 2.23 & 0.78 & 0.84 & 4.20 & 1.97 & 0.73 & 0.81 & 51.840 & 3.80 & $<0.001$ & -0.42 \\
\hline Organised studying & 2.84 & 0.82 & 0.70 & 3.50 & 3.29 & 0.76 & 0.73 & 46.205 & 3.75 & $<0.001$ & 0.61 \\
\hline
\end{tabular}


Table 3 Correlations of the dimensions

\begin{tabular}{|c|c|c|c|c|c|c|c|c|}
\hline & PF1 & PF2 & OR1 & OR2 & ST1 & ST2 & IL1 & IL2 \\
\hline PF1 Psychological flexibility 1 & 1 & & & & & & & \\
\hline PF2 Psychological flexibility 2 & $.653^{* *}$ & 1 & & & & & & \\
\hline OR1 Organised studying 1 & $.465^{* *}$ & $.251^{*} *$ & 1 & & & & & \\
\hline OR2 Organised studying 2 & $.273^{* *}$ & $.463 * *$ & $.589 * *$ & 1 & & & & \\
\hline ST1 Stress 1 & $-.555 * *$ & $-.458 * *$ & $-.411 * *$ & $-.182 *$ & 1 & & & \\
\hline ST2 Stress2 & $-.410 * *$ & $-.514 * *$ & $-.252 * *$ & $-.318 * *$ & $.684 * *$ & 1 & & \\
\hline IL1 Illbeing1 & $-.443 * *$ & $-.469 * *$ & $-.381 * *$ & $-.257 * *$ & $.825 * *$ & $.707 * *$ & 1 & \\
\hline IL2 Illbeing2 & $-.314 * *$ & $-.502 * *$ & $-.210 *$ & $-.313 * *$ & $.613 * *$ & $.818 * *$ & $.768 * *$ & 1 \\
\hline
\end{tabular}

$* *=p<0.01, *=p<0.05$

of the students totally or partly agreed that the course positively affected their studying.

\section{Students' Reflections of the Effects of the Course}

To explore students' reflections in more detail we analyzed students' final reflective journals $(n=97)$ by using qualitative content analysis. This analysis showed that students had benefited from the course in several ways. Table 4 shows the categories and their descriptions, and quotations demonstrating the category. Only one student criticized the course and felt that the course had not helped in studying or reducing stress. All the other students $(n=96)$ reported a range of benefits of the course, and commented from 1 to 8 on the categories presented in Table 4, meaning that the course had at least some positive effect on their well-being or studying.

A total of 70 of the students felt that they experienced the exercises in the course positively and that the course had improved their studying. Students reported that their studying was more effective and motivating and that they had learned new learning techniques. In addition, $61 \%$ of the students reported having learned time management skills in studying. Furthermore, $68 \%$ of the students felt that the course had increased their well-being. Students reported that the exercises in this course had given them tools which have resulted in a decrease in their stress levels and better well-being. Considering their values after doing the time management task had been effective and enlightening for $64 \%$ of the students and had helped them to take actions in their lives. A total of $60 \%$ of the students reported having learnt to pay attention and to manage their negative thoughts, and this had positive effects on their well-being. In addition, $67 \%$ of the students reported having learned new things about themselves and $57 \%$ reported that their thinking has changed comprising comments like they had learned to think about themselves from a new perspective or they have changed their attitude towards studying or other life areas. In addition, $46 \%$ of the students reported that they had learned mindfulness presence comprising better concentration in general and in studying and stressful events.

A total of $23 \%$ of the students felt they were not sure how much the course had affected their well-being (Table 4). The reasons for this were an adequate level of well-being already when they started the course, the content of the course was already familiar, the timing of the course came when they were very busy, or the students had mental problems which prevented them from gaining benefit from the course. However, all students but one benefited from the course in some way or another.

\section{Discussion}

The aim of this study was to explore students' experiences and describe the change in their well-being and studying during the ACT-based intervention course. We also explored the changes in students' experiences of psychological flexibility, well-being, perceived stress and organized studying.

The results of this study showed that students' experiences of this course were mostly very positive, and they felt that the course benefited them in various ways, resulting in better experiences of well-being, studying and time management. The results also suggested that students' experiences of ill-being and stress were significantly lower after the course, whereas students' experience of organized studying and psychological flexibility were higher at the end of the course. Next, we discuss the results in a more detailed way.

The qualitative data of this study suggests that most students reported several positive experiences of this ACT-based course. Most students reported in their reflective journals that they felt an improvement in well-being associated with the completion of the course. In addition, many students reported that they felt their stress had decreased after completing the course and they reported that they had learnt many tools for stress management. The effects of ACT interventions in coping with stress as well as positive effects on well-being have 
Table 4 The categories describing students' experiences of the effects of the course

Category Description of the category Quatation $\quad n^{*} \%$

Improved studying Comments related to improved, more effective and productive studying, and learning new study techniques during this course. Students' study-motivation had increased and attitude towards studies was more positive and they were more goal-oriented after this course.

Increased well-being

Comments where students' well-being had increased and stress decreased during this course thanks to the exercises and assignments of this course. Which were part of this intervention.

Increased self-knowledge

Comments related to learning new things about themselves as a student; learning to understand one's actions better, realising the targets of the development in studying and identifying strengths as a student.

Values and committed Comments where students had thought and become actions conscious of their values and matters which really were important to the them. Students realised that over-perform is not needed also things other than studying were important to them (like family, friends, one's own health).

Time-management and Comments where students expressed that they had learnt to planning plan and manage their time usage better, and had learnt to use calendars. Time-management exercise had been enlightening, and after doing this it was easier to do improvements to time management.

Accepting and Comments related to learning to recognizing, confronting confronting negative and managing negative thoughts and feelings, and thoughts and feelings learning to see thoughts just as thoughts and to observing thoughts. Students had understood how they can choose to think better thoughts.
Change in thinking

Mindful presence

No dramatic change to well-being
Comments related to learning to think in a new way or from new perspectives about themselves, or about the attitude students had towards the studies, life, or themselves. Students had learnt to be more kind and merciful to themselves or acquired more positive attitude towards themselves.

Comments related to learning retreating and realising the significance of being present. Students had learnt to concentrate and to support their ability to concentrate in studying or stressful events.

Consisted of those students comments where they were unsure how much this course affected to their well-being, or where they felt that their well-being was about the same before and after the course.
"I feel that I'm able to manage better my studies and $68 \quad 70$ my everyday life. I believe that this is because I have more effective studying and learning now and this has helped me. During this course I got more motivation towards my studies and some useful tips what to do, if you have problems with your studies" (Student 4).

"Thanks to this course I am able to deal with my stress, 6668 and what really matters me in addition of studying.. I have learnt to relax.. My well-being has increased thanks to better stress management. I'm less stressed after this course, and that is a really good thing!" (Student 10).

"One very important insight was to realise that I dwell 6567 too much on unfinished study things. I have to finish things, or to decide that tonight I'm not going to do anything related to studying but relax and spend spare time. The assignments and practices in this course have made me to understand my shortages and faults in my actions and thinking" (Student 57).

"I learnt to understand and consider which is really important for me in my life and that for example constant and needles performing is not necessary" (Student 48).

"Absolutely the most important thing which I learnt during this course was time management and assessing my time use critically" (Student 16)

"It was totally a new idea for me that you can let your $58 \quad 60$ thoughts to go, or that you can observe your thoughts like an outsider. Understanding this has helped me so much to confront and to be with my negative thoughts. So far, I have always felt that these thoughts do not leave me alone. Now I have learnt not to buy all the thoughts I have.. I had never before understood that I could let my thoughts to go and observe them like an outstander. I have got help to manage my thoughts." (Student 20).

"During this course I learnt to find good things from my everyday life and to pay more attention to these good things instead of brooding of bad things. All in all my thinking has changed in a way I even don't understand. I feel I have grown mentally during this course and learnt to see life and its possibilities in a new way" (Student 6).

"The exercises related to mindful being and mindfulness helped me to calm down and being present at the moment in stressful events" (Student 9)

"It is difficult to say, if this course would have been more beneficial [increasing well-being] for me, if I had invested more to this course. Now I had five other courses at the same time and this course got swamped under this courses... The workload of this period was just too much for me. I was not able to schedule this course to my timetable" (Student 95).

*Total number of the students $n=97, n=$ the number of students who mentioned the theme,

$* * \%=$ the proportion of the students who mentioned the category 
also been shown in earlier studies (Galante et al., 2018; Levin et al., 2017; Räsänen et al., 2016; Waters et al., 2017).

Furthermore, the qualitative analysis of students' reflections brought up the core processes of psychological flexibility and their significance in fostering students' well-being and studying, and to support this, scores of psychological flexibility were also higher at the end of the course than in the beginning of the course. Our study did not include a control group so this result has to be taken with certain reservations but it supports the students' qualitative reflections. However, the positive change in psychological flexibility has been shown in other ACT-based interventions with experimental design (Grégoire et al., 2018; Viskovich \& Pakenham, 2018).

One core process of psychological flexibility is values, and values are the foundation for fostering psychological flexibility (Hayes et al., 2006). This core process and its relevance were present in students' reflections. Over half of the students reported in their reflective journal that they experienced that they had become conscious of their own values or had considered them in more detail during the course. Students also realized the wide variety of important things in their life and would need to make changes in their actions. This exploration of values is an essential part of psychological flexibility as values offer guidance to experiences of meaningfulness in life and help guide actions in a way that offers long-term satisfaction to actions (Hayes et al., 2006). Value-based action and behaviour is necessary for life satisfaction and an experience of a meaningful life (LeJeune \& Luoma, 2019; Luoma \& Hayes, 2008). Exploring one's values is also important because it has been shown that students' actions which focus on short-term rather than long-term value-based satisfaction are related to academic stress, mental problems, and to problems in studying (Levin et al., 2018), and further, increasing value-based action can reduce struggling and suffering (Gloster et al., 2017). These studies support our results, which show that when students became conscious of their own values, it helped them to guide their life and actions in a meaningful way and guide them toward important things in their lives.

Students also reported that they had learnt to recognize and confront their negative thoughts and feelings and that they had come to understand that they were not facts but merely ideas and thoughts. These comments are related to the core process of defusion in psychological flexibility (Luoma \& Hayes, 2008), which has been stated to be the central process in psychological flexibility and in explaining changes in well-being (Ruiz, 2012). When thoughts are seen as facts as they normally very often are, they can be very harmful to behavior (Masuda et al., 2004). Students' descriptions suggest that students had learnt to make a distinction between facts and feelings, and their thoughts are not necessarily facts, which presents cognitive defusion. Furthermore, students reported that they had learnt to accept and confront their negative thoughts.
This represents the core process of acceptance (Hayes, 2019), where negative thoughts and feelings are actively embraced and explored from an observer perspective (Hacker et al., 2016; Hayes et al., 2006). Acceptance is seen as very important for value-based actions (Wilson \& Murrell, 2004) as difficult thoughts and emotions are seen as a central part of life and resisting and avoiding them can result in problems in life (Wilson \& Murrell, 2004). Students reported that acceptance and coping with negative feelings also improved their wellbeing. Just being aware of thought is not always enough to have long-term effects, but acceptance of these experiences and thoughts is important and this can have long-term effects on well-being (Kohtala et al., 2018). Accepting and confronting one's thought may have helped students to study more effectively and be more motivated at university.

Furthermore, students reported that they had learnt mindfulness and being present and had practiced concentration skills in the course, and further, they felt that these skills had helped them in their studies and in stressful events. Being present is a central core process of psychological flexibility (Hayes, 2019; Hayes et al., 2006). Focusing on the present moment may provide opportunities to learn from a current experience and to see new options for action (LeJeune \& Luoma, 2019). In addition, many studies have illustrated the health effects of mindfulness-based interventions (see Grossman et al., 2004), and the results of our study also showed that almost half of the students experienced exercises concerning mindful presence and relaxation to be useful in promoting their well-being by releasing stress. It has been shown that acceptance of thoughts and feelings combined with mindful presence and action have long-term effects on their subjective well-being (Kohtala et al., 2018).

Many students also reported about increasing selfknowledge; students had learnt to know themselves better, and they had realized new and often positive things about themselves during this intervention. They also reported that during this course they had learnt self-compassion. The process of seeing oneself as a context relates to an ongoing process of self-knowledge, and is one core process of psychological flexibility (Hayes et al., 2020). Thus, students reporting that their self-knowledge has improved could be expected in an ACT-based course. In addition, it has been stated that selfcompassion is implicitly processed as part of all core processes ACT (Luoma \& Platt, 2015). For example, acceptance involves self-acceptance, defusion comprises the process of recognizing and distancing critical thoughts about oneself, and one's self as context exercises often include practicing more empathetic ways to relate to oneself (Luoma \& Platt, 2015). A recent study among university students also showed that selfcompassion was significantly correlated with psychological flexibility and emotional well-being (Marshall \& Brockman, 2016). Thus, practicing ACT-based processes can also improve self-compassion toward oneself as was seen in this 
study when students reported that they had learnt to be kinder and more compassionate toward themselves. Thus, incorporating compassion processes in a course for university students may lead to improved outcomes (Marshall \& Brockman, 2016), and should be included in forthcoming courses

Psychological flexibility can also foster learning as it has been shown to be positively related to positive emotions in learning, integration into studying, self-regulation and study progression (Asikainen, 2018; Asikainen et al., 2018; Eisenbeck et al., 2019). Our study reinforces the role of psychological flexibility in learning, and in well-being. Psychological flexibility correlated positively with organized studying and negatively with perceived stress and ill-being, whereas stress correlated negatively with organized studying, and further, there was a negative correlation between ill-being and organized studying. These associations are in line with previous studies that show a positive relationship between psychological flexibility and well-being (Hayes, 2019; Marshall \& Brockman, 2016). The relationship between organized studying and well-being has not been researched much, but recent studies have indicated that organized studying is positively related to psychological flexibility (Asikainen et al., 2019) and well-being (Asikainen et al., 2020). Students' reflections on the course support this finding, as the majority of the students felt that the course benefited their studying. Students felt that during their course their studying became more effective and productive, partly because they had learnt to confront their thoughts as well as clarified their values. As a consequence, they felt that their study-motivation increased and their attitude toward studies was more positive, which is in line with an earlier study (Asikainen, 2018).

Students also considered that their time management skills improved during the course. By including a follow-up of their time usage in this intervention it was possible to make the time usage visible for students. This in turn seemed to be useful for students to make changes to their time management and make their studying more organized. This result is in line with a previous study (Asikainen et al., 2019), which also indicated that with courses like this it is possible to improve students' time management skills.

To conclude, we can suggest that both practicing psychological flexibility and study skills was an excellent way to support students' studying. We propose that better learning is not merely a consequence of learning new studying techniques. It also requires becoming familiar with one's own thoughts and emotions as well as practicing value-based action. It has been shown that psychological flexibility has a strong relationship to progression in studying (Asikainen, 2018; Asikainen et al., 2018) and a negative relationship to problems in studying (Levin et al., 2018) and procrastination (Glick et al., 2014). In addition, psychological flexibility together with organized studying have also been found to be negatively related to procrastination (Hailikari et al., 2021), and thus, by combining these two in this course may have influenced students' experiences of more motivating and more efficient studying as the students reflected in their journals. Based on the reflections of the students, we suggest that supporting both psychological flexibility and study skills can have positive effects on students' well-being and study skills.

Some of the students felt that the course was not useful in improving their well-being. Among the reasons for this were that the students did not have enough time to put an effort into the exercises, they already felt good about their lives, or they had mental health problems. A study where ACT-based intervention was given to clinical psychology students and their experiences were explored with qualitative data showed that $59 \%$ of the students reported some challenges or difficulties in the intervention (Pakenham \& Stafford-Brown, 2012). These difficulties were mostly related to difficulties in understanding the principles of ACT, but the $14 \%$ of the students reporting challenges said that they had difficulties finding the time to fully attend the intervention (Pakenham \& Stafford-Brown, 2012). It has been shown that the amount of effort students put into an exercise is related to their experiences of the usefulness of the intervention course (Asikainen et al., 2020). Thus, if students do not put effort into the exercises, the effect of and experiences of the course may not be so positive.

Furthermore, some of the students reported having mental health problems and reported that their well-being was not increased. It has been shown that participants from different backgrounds can experience interventions differently (Kinnunen et al., 2019). For example, students with severe burnout symptoms do not necessarily show a significant decrease in such symptoms, but they do show an increase in mindfulness skills (Kinnunen et al., 2019). This could also be true for students who had mental health problems at the beginning of the course and felt that their wellbeing had not improved. However, only one student felt that the intervention did not help in any way. Future research should focus more closely on students who do not benefit from courses of this kind, and how this kind of intervention would benefit students with different situations. In forthcoming studies, it would also be interesting to analyze students' reflective essays to study their experiences throughout the course. In the future, the course could be developed so that it is made more visible to the students that the effort put into the course can affect the benefits and their experiences of the course. In addition, for students with problems with mental health additional support could be offered in the course by including information about other support givers, such as university health services and study psychologists. In this way we could capture the students in need of help early on in the course. 


\section{Limitations}

Our study has a number of limitations. It lacked a control group and the change in students' experiences was measured before and after the course, and no long-term effects were measured. For this reason, no causality or effect of the course can be suggested based on the quantitative data, which could have been more properly analyzed with a randomized controlled design with a control group. Due to the lack of experimental design, there is also a possibility for different kinds of problems in interpreting the results, such as the placebo effect, demand characteristics, or spontaneous recovery, thus the quantitative results should be interpreted with care. However, the strength of this study is the qualitative data about students' experiences of the course and the changes in the dimensions were very much in line with the qualitative data. The qualitative data answered the question in what ways did the students feel that the course affected their well-being and studying and, thus, it can be suggested that in this study we obtain the students' own experiences of the effect of the course. The strength of a mixed-method design is that it can provide a more in-depth picture about the research topic and deepen the quantitative findings (Johnson \& Onwuegbuzie, 2004). Thus, even without a control group we suggest that the course had an impact on the students. This study was also based only on self-report data, without any biophysical data. Future research should explore the effects of the course by using biophysical measurements to gain a wider picture of the effects, especially focusing on the long-term effects of these kinds of courses.

\section{Conclusions}

Our results show that students benefited from the course both in terms of studying and well-being. Developing students' psychological flexibility had several benefits for studying and well-being. Thus, we suggest that in order to support successful studying in higher education, both student wellbeing and student study skills should be supported. We suggest that the ACT-based exercises would be worth to add to higher education curriculums. Exercises based on the improvement of psychological flexibility could be easily implemented in curriculums or in separate courses like the one used in the present study. These courses can serve as an early support model for university students when students in deep distress can be recognized quite early in their university careers.

Data Availability Statement The data is available on request.

Funding Open access funding provided by University of Helsinki including Helsinki University Central Hospital.

\section{Declarations}

Conflict of Interest On behalf of all authors, the corresponding author states that there is no conflict of interest.

Ethical Statement This study followed the ethical principles of research with human participants and ethical review in the human sciences in Finland (Finnish National Bord on Research Integrity TENK guidelines 2019).

Informed Consent Informed consent was collected from the participants and participation to this study was voluntary.

Open Access This article is licensed under a Creative Commons Attribution 4.0 International License, which permits use, sharing, adaptation, distribution and reproduction in any medium or format, as long as you give appropriate credit to the original author(s) and the source, provide a link to the Creative Commons licence, and indicate if changes were made. The images or other third party material in this article are included in the article's Creative Commons licence, unless indicated otherwise in a credit line to the material. If material is not included in the article's Creative Commons licence and your intended use is not permitted by statutory regulation or exceeds the permitted use, you will need to obtain permission directly from the copyright holder. To view a copy of this licence, visit http://creativecommons.org/licenses/by/4.0/.

\section{References}

ACHA-National College Health Assessment II: Reference group executive summary Spring (2011). American College Health Association.

Andrews, A., \& Chong, J. L. Y. (2011). Exploring the well-being of students studying at an Australian University. Journal of the Australian and New Zealand Student Services Association, 37, 9 38.

Asikainen, H. (2018). Examining indicators for effective studying: The interplay between student integration, psychological flexibility and self-regulation in learning. Psychology, Society, \& Education, 10(2), 225-237. https://doi.org/10.25115/psye.v10i2.1873.

Asikainen, H., Hailikari, T., \& Mattsson, M. (2018). The interplay between academic emotions, psychological flexibility and selfregulation as predictors of academic achievement. Journal of Further and Higher Education, 42(4), 439-453. https://doi.org/10. 1080/0309877X.2017.1281889.

Asikainen, H., Kaipainen, K., \& Katajavuori, N. (2019). Understanding and promoting students' well-being and performance in university studies. Journal of University Teaching \& Learning Practice, 16(5), $1-15$.

Asikainen, H., \& Katajavuori, N. (2021). Development of a web-based intervention course to promote students' well-being and studying in universities: A protocol for an experimental study design. JMIR Research Protocols, 10(3), e23613. https://doi.org/10.2196/23613.

Asikainen, H., Parpala, A., Lindblom-Ylänne, S., Vanthournout, G., \& Coertjens, L. (2014). The development of approaches to learning and perceptions of the teaching-learning environment during bachelor level studies and their relation to study success. Higher Education Studies, 4(4), 24-36. https://doi.org/10.5539/hes. $\mathrm{v} 4 \mathrm{n} 4 \mathrm{p} 24$.

Asikainen, H., Salmela-Aro, K., Parpala, A., \& Katajavuori, N. (2020). Learning profiles and their relation to study-related burnout and academic achievement among university students. Learning and Individual differences, 78, 101781. https://doi.org/10.1016/j.lindif. 2019.101781. 
A-Tjak, J. G. L., Davis, M. L., Morina, N., Powers, M. B., Smits, J. A., \& Emmelkamp, P. M. (2015). A meta-analysis of the efficacy of acceptance and commitment therapy for clinically relevant mental and physical health problems. Psychotherapy and Psychosomatics, 84(1), 30-36. https://doi.org/10.1159/000365764.

Bond, F., Joda, L., \& Guenole, N. (2013). The work-related acceptance and action questionnaire (WAAQ): Initial psychometric findings and their implications for measuring psychological flexibility in specific contexts. Journal of Occupational and Organizational Psychology, 86(3), 331-347. https://doi.org/10.1111/joop.12001.

Bond, F.W., Flaxman, P.E., van Veldhoven, M.J.P.M., \& Biron, M. (2010). The impact of psychological flexibility and acceptance and commitment therapy (ACT) on health and productivity at work. In J. Houdmont \& S. Leka (Eds.), Contemporary Occupational Health Psychology: Global Perspectives on Research, Education, and Practice, Wiley-Blackwell, Chichester, UK

Cohen, S., Kamarck, T., \& Mermelstein, R. (1983). A global measure of perceived stress. Journal of Health and Social Behavior, 24(4), 385-396. https://doi.org/10.2307/2136404.

Danitz, S. B., \& Orsillo, S. M. (2014). The mindful way through the semester: An investigation of the effectiveness of an acceptancebased behavioral therapy program on psychological wellness in first-year students. Behavior Modification, 38(4), 549-566. https:// doi.org/10.1177/0145445513520218.

Danitz, S., Suvak, M., \& Orsillo, S. (2016). The Mindful Way Through the Semester: Evaluating the Impact of Integrating an AcceptanceBased Behavioral Program Into a First-Year Experience Course for Undergraduates. Behavior Therapy, 47 (4), 487-499. https://doi. org/10.1016/j.beth.2016.03.002.

Dionne, F. (2016). Using acceptance and mindfulness to reduce procrastination among university students: Results from a pilot study. Revista Prâksis, 1, 8-20. https://doi.org/10.1002/jclp.22656.

Dodge, R., Daly, A., Huyton, J., \& Sanders, L. (2012). The challenge of defining well-being. International Journal of Well-being, 2(3), 222 235. https://doi.org/10.5502/ijw.v2i3.4.

Eisenbeck, N., Carrenob, D. F., \& Uclés Juárezb, U. (2019). From psychological distress to academic procrastination: Exploring the role of psychological inflexibility. Journal of Contextual Behavioral Science, 13, 103-108. https://doi.org/10.1016/j.jcbs.2019.07.007.

Elo, S., Kääriäinen, M., Kanste, O., Pölkki, T., Utriainen, K., \& Kyngäs, H. (2014). Qualitative content analysis: A focus on trustworthiness. SAGE Open, 4, 215824401452263. https://doi.org/10.1177/ 2158244014522633

Elo, S., \& Kyngäs, H. (2008). The qualitative content analysis process. Journal of Advanced Nursing, 62(1), 107-115. https://doi.org/10. 1111/j.1365-2648.2007.04569.x.

Evans, C., Connell, J., Audin, K., Sinclair, A., \& Barkham, M. (2005). Rationale and development of a general population well-being measure: Psychometric status of the GP-CORE in a student sample. British Journal of Guidance \& Counselling, 33(2), 153-173. https://doi.org/10.1080/03069880500132581.

Flaxman, P., Bond, F., Livheim, F., \& Hayes, S. (Eds.). (2013). The mindful and effective employee: An acceptance and commitment therapy training manual for improving well-being and performance. New Harbinger Publishers.

French, K., Kolijani-Moghaddam, N., \& Schröder, P. (2017). What is the evidence for the efficacy of self-help acceptance and commitment therapy? A systematic review and meta-analysis. Journal of Contextual Behavioral Science, 6(4), 360-374. https://doi.org/10. 1016/j.jcbs.2017.08.002.

Gagnon, J., Dionne, F., \& Pychyl, T. A. (2016). Committed action: An initial study on its association to procrastination in academic settings. Journal of Contextual Behavioral Science, 5(2), 97-102. https://doi.org/10.1016/j.jcbs.2016.04.002.

Galante, J., Dufour, G., Vainre, M., Wagner, A. P., Stochl, J., Benton, A., Lathia, N., Howarth, E., \& Jones, P. (2018). A mindfulness-based intervention to increase resilience to stress in university students (the mindful student study): A pragmatic randomised controlled trial. The Lancet Public Health, 3(2), e72-e81. https://doi.org/10.1016/ S2468-2667(17)30231-1.

Glick, D. M., Millstein, D. J., \& Orsillo, S. M. (2014). A preliminary investigation of the role of psychological inflexibility in academic procrastination. Journal of Contextual Behavioral Science, 3(2), 8188. https://doi.org/10.1016/j.jcbs.2014.04.002.

Gloster, A. T., Ciarrochi, J., Eifert, G., Sonntag, R., Wittchen, H. U., \& Hoyer, J. (2017). Increasing valued behaviors precedes reduction in suffering: Findings from a randomized controlled trial using ACT. Behaviour Research and Therapy, 91, 64-71. https://doi.org/10. 1016/j.brat.2017.01.013.

Grégoire, S., Lachance, L., Bouffard, T., \& Dionne, F. (2018). The use of acceptance and commitment therapy to promote mental health and school engagement in university students: A multisite randomized controlled trial. Behavior Therapy, 49(3), 360-372. https://doi.org/ 10.1016/j.beth.2017.10.003.

Grossman, P., Niemann, L., Schmidt, S., \& Walach, H. (2004). Mindfulness-based stress reduction and health benefits: A metaanalysis. Journal of Psychosomatic Research, 57(1), 35-43. https://doi.org/10.1016/S0022-3999(03)00573-7.

Hacker, T., Stone, P., \& Macbeth, A. (2016). Acceptance and commitment therapy - Do we know enough? Cumulative and sequential meta-analyses of randomized controlled trials. Journal of Affective Disorders, 190, 551-565. https://doi.org/10.1016/j.jad.2015.10. 053.

Häfner, A., Oberst, V., \& Stock, A. (2014). Avoiding procrastination through time management: An experimental intervention study. Educational Studies, 40(3), 352-360. https://doi.org/10.1080/ 03055698.2014 .899487$.

Hailikari, T., Katajavuori, N., \& Asikainen, H. (2021). Understanding procrastination: A case of a study skills course. Social Psychology of Education. https://doi.org/10.1007/s11218-021-09621-2.

Hailikari, T., \& Parpala, A. (2014). What impedes or enhances my studying? The interaction between approaches to learning, factors influencing study progress and earned credits. Teaching in Higher Education, 19(7), 812-824. https://doi.org/10.1080/13562517. 2014.934348.

Hayes, S. (2019). Acceptance and commitment therapy: Towards a unified model of behavior change. World Psychiatry: Official Journal of the World Psychiatric Association, 18(2), 226-227. https://doi org/10.1002/wps.20626

Hayes, S., Law, S., Malady, M., Zhu, Z., Bai, X., \& X. (2020). The centrality of sense of self in psychological flexibility processes: What the neurobiological and psychological correlates of psychedelics suggest. Journal of Contextual Behavioral Sciences, 15, 30 38. https://doi.org/10.1016/j.jcbs.2019.11.005.

Hayes, S., Luoma, J., Bond, F., Masuda, A., \& Lillis, J. (2006). Acceptance and commitment therapy: Model, processes, and outcomes. Behaviour Research and Therapy, 44(1), 1-25. https://doi. org/10.1016/j.brat.2005.06.006.

Howell, A., \& Passmore, H. (2019). Acceptance and commitment training (ACT) as a positive psychological intervention: A systematic review and initial meta-analysis regarding ACT's role in wellbeing promotion among university students. Journal of Happiness Studies, 20, 1995-2010. https://doi.org/10.1007/s10902-018-00277.

Johnson, R. B., \& Onwuegbuzie, A. J. (2004). Mixed methods research: A research paradigm whose time has come. Educational Researcher, 33(7), 14-26. https://doi.org/10.3102/ 0013189 X033007014.

Keyes, C. (1998). Social well-being. Social Psychology Quarterly, 61(2), 121-140. https://doi.org/10.2307/2787065. 
Keyes, C. (2002). The Mental Health Continuum: From Languishing to Flourishing in Life. Journal of Health and Social Behavior, 43(2), 207.

Kinnunen, S. M., Puolakanaho, A., Tolvanen, A., Mäkikangas, A., \& Lappalainen, R. (2019). Does mindfulness-, acceptance-, and value-based intervention alleviate burnout? A person-centered approach. International Journal of Stress Management, 26(1), 89101. https://doi.org/10.1037/str0000095.

Kohtala, A., Muotka, J., \& Lappalainen, R. (2018). Changes in mindfulness facets and psychological flexibility associated with changes in depressive symptoms in a brief acceptance and value based intervention: An exploratory study. International Journal of Psychology and Psychological Therapy, 18(1), 83-98.

LeJeune, J., \& Luoma, J. B. (2019). Values in therapy: A clinician's guide to helping clients explore values, increase psychological flexibility, and live a more meaningful life. New Harbinger Publications.

Levin, M., Krafft, J., Hicks, E., Pierce, B., \& Twohig, M. (2020). A randomized dismantling trial of the open and engaged components of acceptance and commitment therapy in an online intervention for distressed college students. Behaviour Research and Therapy, 126. https://doi.org/10.1016/j.brat.2020.103557.

Levin, M. E., Haeger, J. A., Ong, C. W., \& Twohig, M. P. (2018). An examination of the transdiagnostic role of delay discounting in psychological inflexibility and mental health problems. The Psychological Record, 68(2), 201-210. https://doi.org/10.1007/ s40732-018-0281-4.

Levin, M. E., Haeger, J. A., Pierce, B. G., \& Twohig, M. P. (2017). Webbased acceptance and commitment therapy for mental health problems in college students: A randomized controlled trial. Behavior Modification, 41(1), 141-162. https://doi.org/10.1177/ 0145445516659645.

Luoma, J. \& Hayes, S. (2008). Cognitive defusion. In W.T. O’Donohue $\&$ J.E. Fisher (Eds.), Cognitive behavior therapy: Applying empirically supported techniques in your practice (2nd ed.), John Wiley \& Sons Inc. 2008, pp. 83-90.

Luoma, J., \& Platt, M. (2015). Shame, self-criticism, self-stigma, and compassion in Acceptance and Commitment Therapy, Current Opinion in Psychology, 2, 97-101. https://doi.org/10.1016/j. copsyc.2014.12.016.

Marshall, E.-J., \& Brockman, R. (2016). The relationships between psychological flexibility, self-compassion, and emotional well-being. Journal of Cognitive Psychotherapy, 30(1), 60-72. https://doi.org/ 10.1891/0889-8391.30.1.60.

Masuda A., Hayes, S., Sackett, C. \& Twohig, M. (2004). Cognitive defusion and self-relevant negative thoughts: examining the impact of a ninety year old technique. Behaviour Research and Therapy, 42(4), 477-485. https://doi.org/10.1016/j.brat.2003.10.008.

Nimon, K. (2012). Statistical assumptions of substantive analyses across the general linear model: A mini-review. Frontiers in Psychology, 3, 322. https://doi.org/10.3389/fpsyg.2012.00322.

Pakenham, K., \& Stafford-Brown, J. (2012). Postgraduate clinical psychology students' perceptions of an acceptance and commitment therapy stress management intervention and clinical training. Clinical Psychologist, 17(2), 56-66. https://doi.org/10.1111/j. 1742-9552.2012.00050.x.

Parpala, A., \& Lindblom-Ylänne, S. (2012). Using a research instrument for developing quality at the university. Quality in Higher Education, 18(3), 313-328. https://doi.org/10.1080/13538322. 2012.733493
Pistorello, J. (Ed.). (2012). Mindfulness \& acceptance for counselling college students: Theory and practical applications for intervention, prevention and outreach. New Harbinger Publications, United States.

Pope, C., Ziebland, S., \& Mays, N. (2000). Analysing qualitative data. British Medical Journal, 320(7227), 114-116. https://doi.org/10. 1136/bmj.320.7227.114.

Puolakanaho, A., Tolvanen, A., Kinnunen, S., \& Lappalainen, R. (2020). A psychological flexibility-based intervention for burnout: A randomized controlled trial. Journal of Contextual Behavioral Science, 15, 52-67. https://doi.org/10.1016/j.jcbs.2019.11.007.

Räsänen, P., Lappalainen, R., Muotka, J., Tolvanen, A., \& Lappalainen, R. (2016). An online guided ACT intervention for enhancing the psychological well-being of university students: A randomized controlled clinical trial. Behaviour Research and Therapy, 78(March), 30-42. https://doi.org/10.1016/j.brat.2016.01.001.

Ruiz, F. J. (2010). A review of acceptance and commitment therapy (ACT) empirical evidence: Correlational, experimental psychopathology, component and outcome studies. International Journal of Psychology and Psychological Therapy, 10(1), 125-162.

Ruiz, F. J. (2012). Acceptance and commitment therapy versus traditional cognitive behavioral therapy: A systematic review and metaanalysis of current empirical evidence. International Journal of Psychology \& Psychological Therapy, 12(2), 333-357.

Ryff, C. D. (1989). Happiness is everything, or is it? Explorations on the meaning of psychological well-being. Journal of Personality and Social Psychology, 57, 1069-1081. https://doi.org/10.1037/00223514.57.6.1069.

Rytkönen, H., Parpala, A., Lindblom-Ylänne, S., Virtanen, V., \& Postareff, L. (2012). Factors affecting bioscience students' academic achievement. Instructional Science, 40(2), 241-256. https://doi.org/ 10.1007/s11251-011-9176-3.

Salmela-Aro, K., \& Read, S. (2017). Study engagement and burnout profiles among Finnish higher education students. Burnout Research, 7, 21-28. https://doi.org/10.1016/j.burn.2017.11.001.

Storrie, K., Ahern, K., \& Tuckett, A. (2010). A systematic review: Students with mental health problems - A growing problem. International Journal of Nursing Practice, 16(1), 1-6. https://doi. org/10.1111/j.1440-172X.2009.01813.x.

Vermunt, J. D. (1996). Metacognitive, cognitive and affective aspects of learning styles and strategies: A phenomenographic analysis. Higher Education, 31, 25-50. https://doi.org/10.1007/BF00129106.

Viskovich, S., \& Pakenham, S. I. (2018). Pilot evaluation of a web-based acceptance and commitment therapy program to promote mental health skills in university students. Journal of Clinical Psychology, 74(12), 2047-2069. https://doi.org/10.1002/jclp.22656.

Waters, C. S., Frude, N., Flaxman, P. E., \& Boyd, J. (2017). Acceptance and commitment therapy (ACT) for clinically distressed health care workers: Waitlist-controlled evaluation of an ACT workshop in a routine practice setting. British Journal of Clinical Psychology, 57(1), 82-98. https://doi.org/10.1111/bjc.12155.

Wilson, K. G., \& Murrell, A. R. (2004). Values work in acceptance and commitment therapy: Setting a course for behavioral treatment. In S. C. Hayes, V. M. Follette, \& M. M. Linehan (Eds.), Mindfulness and acceptance: Expanding the cognitive-behavioral tradition (pp. 120 151). Guilford Press.

Publisher's Note Springer Nature remains neutral with regard to jurisdictional claims in published maps and institutional affiliations. 